\title{
Effect of Abutment Connection Type and Cyclic Loading on Removal Torque Value
}

\author{
E Jalalian ${ }^{1}$, E Hashemi ${ }^{2} *$, SH Naser Mostufi ${ }^{3}$, \\ AR Banifatemeh², M Shariati ${ }^{2}$, A Pirmoazen², S Alizadeh ${ }^{4}$
}

1.Associate Professor, Department of Fixed Prosthodontics, Dental Branch, Islamic Azad University, Tehran, Iran

2. Postgraduate Student, Department of Prosthodontics, Dental Branch, Islamic Azad University, Tehran, Iran

3 .Assistant Professor, Department of Fixed Prosthodontics, Dental Branch, Islamic Azad University, Tehran, Iran

4. Prosthodontist, Private Practice, Tehran, Iran

\begin{tabular}{l} 
ARTICLE INFO \\
\hline Article History \\
Received: Nov 2018 \\
Accepted: Dec 2018 \\
ePublished: Jan 2019 \\
Corresponding author:
\end{tabular}

Prosthodontics Dept, Faculty of Dentistry, Tehran Medical Sciences, Islamic Azad University, Tehran, Iran , Hashemi.prostho@ gmail.com

\begin{abstract}
Background and Aim: Maintaining the primary torque of the abutment screw is a common problem related to implant-supported restorations; a failure in this respect often leads to screw loosening. The abutment screw plays a critical role in the longterm stability of restorations. This study aimed to assess the effect of two abutment connection types with and without cyclic loading on removal torque value (RTV).

Materials and Methods: A total of 24 abutments and fixtures were evaluated in this in-vitro experimental study. Two abutments with internal and external connections were tightened to fixtures using a digital torque-meter according to the manufacturer's instructions. Half of the samples were subjected to cyclic loading with a $100-\mathrm{N}$ mechanical load at a $1-\mathrm{Hz}$ frequency $\left(500,000\right.$ cycles) applied at $23 \pm 1^{\circ} \mathrm{C}$ with $50 \pm 5 \%$ humidity. Next, the RTV was measured for each abutment. Two-way analysis of variance (ANOVA) was used to assess the effect of the abutment system and cyclic loading on RTV.

Results: The highest RTV belonged to the internal connection abutment without cyclic loading (22 Newton-centimeter ( Ncm)), while the lowest RTV was noted with the external connection abutment subjected to cyclic loading $(14 \mathrm{Ncm} ; \mathrm{P}<0.01)$. There was no statistically significant interaction effect between the two variables (the abutment system and cyclic loading; $\mathrm{P}=0.839$ ). The $\mathrm{RTV}$ in the internal hexagon abutments was significantly higher than that in the external hexagon abutment system $(\mathrm{P}<0.001)$. Cyclic loading significantly reduced the RTVs in both abutments $(\mathrm{P}<0.001)$.

Conclusion: According to the results, internal connection abutments experience less screw loosening.
\end{abstract}

Key words: Dental Implant-Abutment Design, Dental Implant Loading, Torque,

Mechanical Stress

J Res Dent Maxillofac Sci 2019;4(1):36-40.

DOI: $10.29252 / j r d m s .4 .1 .36$

\section{Introduction:}

Maintaining the primary torque of the abutment screw is a common problem related to implant-supported restorations; a failure in this respect often leads to screw loosening. The stability of the primary torque of the abutment screw plays a crucial role in the long-term durability of restorations and is an important factor in the success

of restorations, particularly in single-tooth restorations. ${ }^{(1)}$ Previous studies have reported varying prevalence rates, ranging from $2 \%$ to $40 \%$, for screw loosening. ${ }^{(2-5)}$ Loose prosthetic screws can cause serious complications such as the formation of granulation tissue between the loose abutment and implant and can result in the for- 
in the formation of fistula and soft tissue infection. Also, loose screws are at a higher risk of fracture.

On the other hand, loosening or fracture of abutment screws can pose serious complications as the overlying restoration must be removed to access the screw. During this process, the cemented implant restoration may be damaged or completely destructed.

Several factors affect the microgap between the implant and abutment, including the implant system, the geometric form of the implantabutment contact, the use of self-cast abutments instead of mechanical types, and the amount of load applied for abutment tightening. Mechanical problems can cause subsequent abutment screw loosening and abutment and implant inefficacy. ${ }^{(6,7)}$

Several techniques have been suggested to decrease the risk of screw loosening, including the application of a proper preload for screws, a narrow occlusal table, centric occlusal contact, smoothing steep cusps, and decreasing the length of the abutment. The type of connection and its design can also affect screw loosening. The external hexagon connection type is more susceptible to screw loosening following the application of dynamic loads due to its mechanical properties. Other advantages of internal connection type compared to external connection include better distribution of forces under mechanical loads, higher stability due to the wider connection area, and higher resistance to lateral forces due to the more inferior position of the center of rotation. ${ }^{(8-10)}$ However, internal connections have disadvantages such as thinner fixture walls at the abutment connection and difficulty in matching the taper of the fixtures. The connection design and the presence/absence of an index at the abutment-implant connection are other influential factors in screw loosening. Some studies have stated that the presence of an index is effective in the prevention of screw loosening due to its anti-rotation property. ${ }^{(11,12)}$ However, some others found no significant difference in the removal torque value (RTV) of abutments with and without an index. ${ }^{(13,14)}$
This study aimed to assess the effect of two implants with different connection types with and without cyclic loading (for simulation of the oral environment) on RTV.

\section{Materials and Methods}

This in-vitro experimental study was conducted on two types of abutments with internal and external connections (BioHorizons, Alabama, USA).

The sample size was calculated to be six in each group (a total of 24) according to a previous study by Cashman et al in $2011,{ }^{(15)}$ assuming the mean screw loosening in the ITI system to be 42.65 with standard deviation (SD) of 2.7 , and the mean value of 36.25 with SD of 2.63 in the test group with $80 \%$ power of study.

A total of 24 abutments and fixtures were evaluated in this study. The abutment with internal hexagon connection had a $4.5-\mathrm{mm}$ diameter, a 5.5-mm height, and a 1-mm collar. The abutment with external hexagon connection had a $4.5-\mathrm{mm}$ diameter, a 5.5-mm height, and a 1-mm collar. Two BioHorizons fixtures were used: one with a 4.5- $\mathrm{mm}$ platform diameter and a $10-\mathrm{mm}$ height with an internal connection with an $11^{\circ}$ taper and a 2.5-mm diameter of hex and the other one with an external connection with the same length and diameter as the first one (Figure 1).

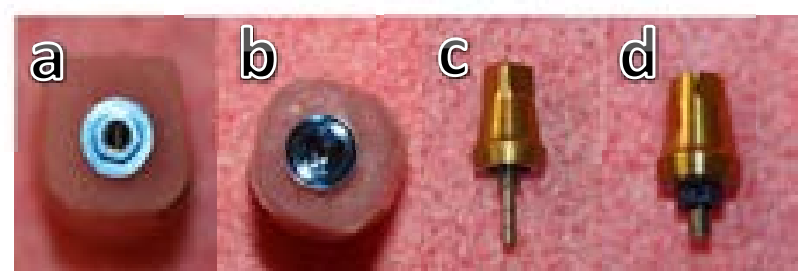

Figure 1.a) External connection.b) Internal connection.c) External abutment. d) Internal abutment

The implants were first mounted in a cylindrical block of auto-polymerizing resin (GC, Tokyo, Japan) with a $1.2-\mathrm{cm}$ diameter and a $1.5-\mathrm{cm}$ height. They were mounted at a $90^{\circ}$ angle for the purpose of standardization using a paralleling device (Ney 4500, Dentsply, USA). ${ }^{(16)}$ 
The block was fixed by a mounting jig, and then, the abutment screws were torqued to $30 \mathrm{Ncm}$ using a digital torquemeter (TQ-680, Insturtherm, Germany) and were tightened to the fixtures. ${ }^{(17)}$ After 10 minutes, the RTV of half of the samples (control group), equally comprising of both internal and external connection types, was measured and recorded. The remaining samples (test group) were subjected to 5,000 thermal cycles between $5-50{ }^{\circ} \mathrm{C}$ (TC300, Vafaei Industrial, Tehran, Iran). ${ }^{(18)}$ Next, the samples were subjected to cyclic loading (Z030, Zwick, Ulm, Germany) with a 100-N mechanical load at a $1-\mathrm{Hz}$ frequency up to 500,000 cycles (corresponding to 20 months of mastication in the clinical setting). The load was applied to the upper part of the abutments. ${ }^{(15)}$ For this purpose, the implant-abutment assembly was held by a holder and cyclic loads were applied at $23 \pm 1^{\circ} \mathrm{C}$ with $50 \pm 5 \%$ humidity. ${ }^{(17)}$ Only half of the samples were subjected to cyclic loading. Afterwards, the RTV of each abutment was measured and recorded (Figure 2).

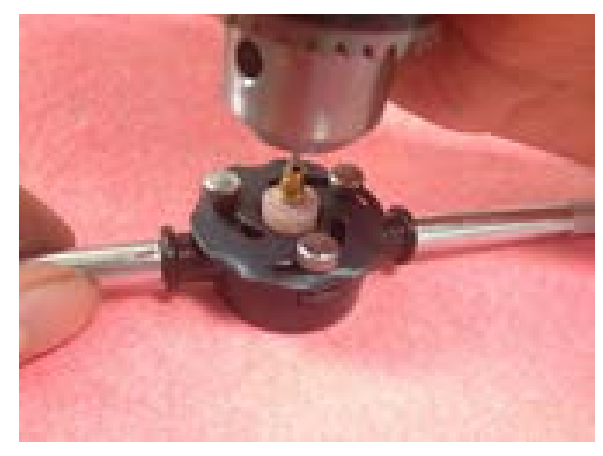

Figure 2. Measuring the removal torque value (RTV) by a torque-meter

Two-way analysis of variance (ANOVA) was used to assess the effect of the abutment system and cyclic loading on RTV. In case of significant differences, one-way ANOVA was used to compare RTV between the two systems. Student t-test was used to compare the RTV in groups with and without cyclic loading. The level of significance was set at 0.05 .

Results:

Table 1 shows the RTV in the groups with two abutment connection types with/without cyclic loading. The maximum RTV was noted in the internal connection group without cyclic loading (22 $\mathrm{Ncm}$ ), and the minimum RTV was noted in the external connection group with cyclic loading (14 Ncm). Two-way ANOVA indicated no statistically significant interaction effect between the two variables (the abutment system and cyclic loading; $\mathrm{P}=0.839$ ). The RTV in the internal hexagon abutments was significantly higher than that in the external hexagon abutment system $(\mathrm{P}<0.001)$. Cyclic loading significantly reduced the RTVs in both abutments $(\mathrm{P}<0.001)$. ANOVA showed that the difference in this respect was statistically significant among the four groups $(\mathrm{P}<0.01)$. Multiple comparisons by Scheffe test exhibited a significant difference among the groups in this respect $(\mathrm{P}<0.01)$. The RTV in the internal connection group without cyclic loading was $22.88 \mathrm{Ncm}$, while this value was $19.68 \mathrm{Ncm}$ in the internal connection group with cyclic loading; the difference (16\%) was statistically significant $(\mathrm{P}<0.01)$.

Table 1: Removal torque value (RTV) based on the abutment connection type and cyclic loading (ANOVA)

\begin{tabular}{cccc}
\hline Abutment connection type & Cyclic loading & Mean \pm SD $(\mathrm{Ncm})$ & $\mathrm{CV}$ \\
\hline \multirow{2}{*}{ Internal hexagon } & Yes & $19.68 \pm 1.12$ & 5.7 \\
\cline { 2 - 4 } & No & $22.83 \pm 1.47$ & 6.4 \\
\hline External hexagon & Yes & $14.21 \pm 1.23$ & 8.6 \\
\cline { 2 - 4 } & No & $17.83 \pm 1.23$ & 7.4 \\
\hline
\end{tabular}

$S D=$ Standard Deviation, $C V=$ Coefficient of Variation, Ncm $=$ Newton-centimeter

The RTV in the external connection abutments without cyclic loading was $17.83 \mathrm{Ncm}$, while this value was $14.21 \mathrm{Ncm}$ in the external connection abutments with cyclic loading; the difference $(25 \%)$ was statistically significant $(\mathrm{P}<0.01)$. The RTV in the internal connection abutments without cyclic loading was $22.83 \mathrm{Ncm}$, while this value was $17.83 \mathrm{Ncm}$ in the external connection abutments without cyclic loading (28\% difference; $\mathrm{P}<0.01)$. The RTV in the internal connection abutments with cyclic loading was $19.68 \mathrm{Ncm}$, 
while this value was $14.21 \mathrm{Ncm}$ in the external connection abutments with cyclic loading (38\% difference; $\mathrm{P}<0.001)$. The coefficient of variation $(\mathrm{CV})$ in all the groups was low and maximally 8.6, which indicated the homogenous distribution of the RTV within the groups.

\section{Discussion:}

Despite numerous studies, it has not been well-documented that which type of implantabutment connection (internal or external hexagon) would have the highest success rate. All implant systems are designed to have adequate strength to tolerate mechanical loads with optimal stability. ${ }^{(19)}$ Studies on the correlation between the abutment connection type and cyclic loading and the effect on RTV are limited. The current study assessed the effect of two implants with different connection types with and without cyclic loading (for simulation of the oral environment) on RTV. The results showed that internal connection, with/without cyclic loading, was superior to external connection, and cyclic loading decreased the RTV.

One important factor in the success of dental implants is the complete adaptation between the fixture and implant abutment. This adaptation is highly important since it decreases the stress applied to the framework, implant, and bone..$^{(1,2)}$ Misfit between the fixture and implant abutment can cause biological complications that lead to periimplantitis, mucosal inflammation, and subsequent bacterial invasion into the microgaps between the fixture and implant abutment. Mechanical complications lead to implant fracture, screw fracture, suprastructure fracture, and screw loosening. ${ }^{(3)}$

Several studies have assessed the effect of cyclic loading on screw loosening and have reported controversial results. ${ }^{(4)}$ Internal connection systems have been designed to decrease screw loosening and screw fracture, which are often seen in external hexagon systems. ${ }^{(19)}$ Some previous studies have shown the optimal efficacy of internal connections compared to external connections. ${ }^{(19)}$ Some others have reported the superiority of external connections, while some researchers found no difference between the two. ${ }^{(19)}$

Over 20 types of implant-abutment connections have been designed to improve the func- tion of internal and external connections. ${ }^{(19)}$ The Morse-taper and hexagon are among the most successful internal connections. Among external connections, hexagon has shown superior results compared to other types. ${ }^{(19)}$

The type of connection has a significant effect on the success of implant abutment and the occurrence of screw loosening. Sailer et al compared the function of zirconia abutments with an internal connection compared to the external connection. ${ }^{(20)}$ They showed that the connection type had a significant effect on the success of zirconia abutments, and the highest resistance was obtained with the use of internal connections by attaching a secondary piece of metal. It seemed that the internal connection was more successful than the external connection, which was in agreement with our findings.

Meticulous studies have shown that the load is more uniformly distributed in internal connection systems compared to external connection systems. ${ }^{(21)}$ Piermatti et al assessed the implant screw torque loss in external hex and internal connection implant systems. ${ }^{(22)}$ The samples were subjected to cyclic loading. The results showed that although internal connections are often preferred by clinicians, no significant difference existed between the two connection types in terms of screw loosening. ${ }^{(22)}$ Their findings were in contrast to ours. It seems that the screw design can affect the resistance to screw loosening. Also, the torque applied and the frequency of cyclic loading affect the occurrence of screw loosening.

Adverse effects of inadequate torque may reveal after several months. It has been reported that increasing the preload of the screw and the clamping force at the joint site is among the most effective methods for decreasing screw loosening. Preload protects the screw against breakage during cyclic loading, and the most efficient preload for implant screw is $60 \%-70 \%$ of the maximum resistance for the respective material. Thus, a 20-35-Ncm load, depending on the implant type, is the most suitable. ${ }^{(22)}$ In the current study, a $30-\mathrm{Ncm}$ load was applied, which was in line with previous reports.

Ribeiro et al compared the success rates of external hexagon, internal hexagon, and cone-incone connections after cyclic loading and showed that external hexagon was superior in terms of fracture resistance of prosthetic components, 
such as abutment screw, although this difference was not statistically significant. ${ }^{(8)}$ Moreover, the external connection was more resistant to fracture than the internal connection due to its type of attachment to the fixture. ${ }^{(8)}$

Researchers have discussed that internal hexagon systems have advantages such as easy connection to the abutment, easy use for one-stage implant installation, high stability in single-tooth restorations, high resistance to lateral forces, and more uniform balance of loads. ${ }^{(21)}$ In the current study, the highest RTV belonged to the internal connection without mechanical loading $(22 \mathrm{Ncm})$, while the lowest RTV belonged to the external connection with mechanical loading $(14 \mathrm{Ncm})$. The RTVs in the internal connection abutments without and with cyclic loading were 22.88 and 19.68 $\mathrm{Ncm}$, respectively, which showed that cyclic loading decreased the RTV.

Tsuge and Hagiwara assessed the effect of cyclic loading on screw loosening of implants with internal and external hexagon connections. ${ }^{(23)}$ The results showed that screw loosening in the internal connection group was less frequent compared to the external connection group, which was in line with our results. Junqueira et al assessed torque loss in pre-machined and cast abutments at the abutment-implant external hexagon after mechanical loading. ${ }^{(24)}$ The results showed that mechanical loading decreased the amount of torque with no significant difference between cast and pre-machined abutments. Thus, it seems that mechanical loading, corresponding to one year of clinical service, decreases the torque irrespective of the type of abutment. (24) Researchers believe that this reduction is smaller in internal connection abutments. Although some researchers did not find a significant difference between internal and external connections, ${ }^{(21)}$ most of them have pointed to the higher efficacy of internal connections such that tapered implants with internal hex connections have a higher resistance to screw loosening compared to external hex connections. ${ }^{(25)}$

A review study by Gracis et al evaluated the efficacy of internal and external connections and showed that the type of implant, connection design, materials, and techniques affect the results. Moreover, screw loosening is mainly due to the inappropriate method of work and more commonly occurs with the use of external connections. ${ }^{(26)}$ Kwon et al studied the effects of implant abutment deformation in three internal connection types with different torque values and showed a significant difference in Xive type under a 45-Ncm load but no difference was noted in MF or Magic grip types. ${ }^{(27)}$ These results revealed that implant abutment design plays an important role in the prevention of implant abutment deformation. Moreover, internal connection abutments have acceptable clinical stability under torque. ${ }^{(27)}$

Cho et al evaluated the effect of cyclic loading on the reverse torque value of internal and external connection implants and indicated that internal connection implants had a better reverse torque value than those with an external connection. (28) Another study, similar to ours, showed inefficacy of implants with an external hexagon connection. ${ }^{(19)}$ The RTV for internal connection tapered implants was $81.6 \%$ without and $85 \%$ with cyclic loading. ${ }^{(19)}$ Our study showed the RTV to be $22.83 \mathrm{Ncm}$ for internal connection abutments without cyclic loading and $17.83 \mathrm{Ncm}$ for external connection abutments without cyclic loading. These values were 19.68 and 14.21 $\mathrm{Ncm}$ for external connection abutments without cyclic loading and for internal connection abutments without cyclic loading, respectively. These values were much lower than those reported in previous studies, which indicates that this type of abutment better preserves the torque. Also, since the internal and external connection abutments used in our study had been manufactured by the same manufacturer, the results can be better generalized.

Feitosa et al assessed the efficacy of internal and external connections and found a significant difference in the fracture strength of external hexagon $(12.8 \mathrm{Ncm})$, internal hexagon (13.8 $\mathrm{Ncm})$, and Morse taper $(18.6 \mathrm{Ncm}) .{ }^{(29)}$ Tsuruta et al studied three types of abutment connection systems, namely, external parallel connection (EP), internal parallel connection (IP), and internal conical connection (CC), from the viewpoint of microleakage from the gap between the implant and abutment and in connection with the loosening of abutment screw. ${ }^{(30)}$ After 2,000 cycles of compressive tensile loadings, the RTV of the abutment screw represented no statistically significant differences among the three groups. 
$(30,31)$

Benjaboonyazit et al evaluated the decreasing pattern of RTVs of a combined cone and octalobule index implant-abutment connection under different numbers of mechanical loading cycles. ${ }^{(32)}$ All experimental groups from 50,000 to $2,000,000$ cycles showed significant decreases in RTVs compared to the control group (without cyclic loading; $\mathrm{P}<0.05)$. The RTVs in the group of 50,000 cycles to $1,800,000$ cycles did not change significantly but there was a significant reduction in the RTVs of the group of 2,000,000 cycles compared to the group of 50,000 cycles $(\mathrm{P}<0.05)$. Each type of connection has its own advantages and disadvantages. An internal connection, due to its design, causes a better distribution of loads. With a tapered connection, lateral loads are received by the tapered design, protecting the thread area of the abutment against the applied loads. On the other hand, an external connection is easy for use in two-step implants and has an anti-rotation system and retrievability. Also, by using this system, the technician can more easily apply porcelain. ${ }^{(20)}$ Also, an external connection confers fracture resistance to the fixture. ${ }^{(26)}$ The type of thread designed for connection also plays an important role in screw loosening. ${ }^{(20)}$ According to the manufacturer of the connections used in the present study, utmost precision has been used in designing the threads.

Evidence shows that an internal connection better contributes to the success of the prosthesis. Increased preload, use of digital-mechanical torque-meters, use of maximum torque to minimize the gap, and use of internal connections increase the success rate of the prosthesis. ${ }^{(29)}$ Furthermore, the clinical success of implant systems relates to factors such as osseointegration, occlusion, saliva, jaw movements, and bone quality. ${ }^{(20)}$ Assessment of two commonly used connection systems, an adequate sample size, and finding significant differences using ANOVA and Scheffe test (indicating the power of the test) were among the strengths of our study. Also, both internal and external connection abutments were from the same manufacturer, which was another strong point of the present study.

This study had an in-vitro design. Thus, the generalization of the results to the clinical setting must be done with caution. More in-vivo studies with a larger sample size are required to compare the RTVs of abutments with internal and external connections.

\section{Conclusion:}

Within the limitations of the present study, the results showed that the internal connection, irrespective of cyclic loading, was superior to the external connection. Cyclic loading decreased the torque value in all cases.

\section{Acknowledgments:}

Special thanks to our teachers and to the laboratory staff of Tehran University of Medical Sciences for their cooperation. This paper was written based on thesis no. $122 / \mathrm{T}$.

\section{References:}

1. Chaar MS, Att W, Strub JR. Prosthetic outcome of cement-retained implant-supported fixed dental restorations: a systematic review. J Oral Rehabil. 2011 Sep;38(9):697-711.

2. Nassar HI, Abdalla MF. Bacterial leakage of different internal implant/abutment connection. Future Dent J. 2015 Dec 1;1(1):1-5.

3. Ricci G, Aimetti M, Stablum W, Guasti A. Crestal bone resorption 5 years after implant loading: clinical and radiologic results with a 2-stage implant system. Int J Oral Maxillofac Implants. 2004 Jul-Aug;19(4):597-602.

4. Goodacre CJ, Bernal G, Rungcharassaeng K, Kan JY. Clinical complications with implants and implant prostheses. J Prosthet Dent. 2003 Aug 1;90(2):121-32.

5. Johansson LA, Ekfeldt A. Implant-supported fixed partial prostheses: a retrospective study. Int J Prosthodont. 2003 Mar-Apr;16(2):172-6.

6. Byrne D, Jacobs S, O'Connell B, Houston F, Claffey N. Preloads generated with repeated tightening in three types of screws used in dental implant assemblies. J Prosthodont. 2006 MayJun;15(3):164-71.

7. Hebel KS, Gajjar RC. Cement-retained versus screw-retained implant restorations: achieving optimal occlusion and esthetics in implant dentistry. J Prosthet Dent. 1997 Jan 1;77(1):28-35.

8. Ribeiro CG, Maia ML, Scherrer SS, Cardoso AC, Wiskott HW. Resistance of three implantabutment interfaces to fatigue testing. J Appl Oral Sci. 2011 Aug;19(4):413-20.

9. Ricomini Filho AP, Fernandes FS, Straioto 
FG, da Silva WJ, Del Bel Cury AA. Preload loss and bacterial penetration on different implantabutment connection systems. Braz Dent J. 2010;21(2):123-9.

10.Harder S, Dimaczek B, Açil Y, Terheyden H, Freitag-Wolf S, Kern M. Molecular leakage at implant-abutment connection-in vitro investigation of tightness of internal conical implant-abutment connections against endotoxin penetration. Clin Oral Investig. 2010 Aug 1;14(4):427-32.

11.Lang LA, Wang RF, May KB. The influence of abutment screw tightening on screw joint configuration. J Prosthet Dent. 2002 Jan 1;87(1):749.

12.Vigolo P, Majzoub Z, Cordioli G. Measurement of the dimensions and abutment rotational freedom of gold-machined 3i UCLA-type abutments in the as-received condition, after casting with a noble metal alloy and porcelain firing. $\mathrm{J}$ Prosthet Dent. 2000 Nov ;84(5):548-53.

13. Theoharidou A, Petridis HP, Tzannas K, Garefis P. Abutment screw loosening in single-implant restorations: a systematic review. Int J Oral Maxillofac Implants. 2008 Jul-Aug;23(4):681-90.

14. Malaguti G, Denti L, Bassoli E, Franchi I, Bortolini S, Gatto A. Dimensional tolerances and assembly accuracy of dental implants and machined versus cast $\square$ on abutments. Clin Implant Dent Relat Res. 2011 Jun;13(2):134-40.

15.Cashman PM, Schneider RL, Schneider GB, Stanford CM, Clancy JM, Qian F. In vitro analysis of post-fatigue reverse-torque values at the dental abutment/implant interface for a unitarian abutment design. J Prosthodont. 2011 Oct;20(7):5039.

16. Siadat H, Pirmoazen S, Beyabanaki E, Alikhasi M. Does abutment collar length affect abutment screw loosening after cyclic loading? J Oral Implantol. 2015 Jul;41(S1):346-51.

17.Kim ES, Shin SY. Influence of the implant abutment types and the dynamic loading on initial screw loosening. J Adv Prosthodont. 2013 Feb 1;5(1):21-8.

18. Yeo IS, Lee JH, Kang TJ, Kim SK, Heo SJ, Koak JY, et al. The effect of abutment screw length on screw loosening in dental implants with external abutment connections after thermocycling. Int J Oral Maxillofac Implants. 2014 Jan-Feb;29(1):59-62.

19.Pintinha M, Camarini ET, Sábio S, Pereira
JR. Effect of mechanical loading on the removal torque of different types of tapered connection abutments for dental implants. J Prosthet Dent. 2013 Nov;110(5):383-8.

20.Sailer I, Sailer T, Stawarczyk B, Jung RE, Hämmerle $\mathrm{CH}$. In vitro study of the influence of the type of connection on the fracture load of zirconia abutments with internal and external implant-abutment connections. Int J Oral Maxillofac Implants. 2009 Sep-Oct;24(5):850-8.

21. Maeda Y, Satoh T, Sogo M. In vitro differences of stress concentrations for internal and external hex implant-abutment connections: a short communication. J Oral Rehabil. 2006 Jan;33(1):75-8. 22.Piermatti J, Yousef H, Luke A, Mahevich R, Weiner S. An in vitro analysis of implant screw torque loss with external hex and internal connection implant systems. Implant Dent. 2006 Dec 1;15(4):427-35.

23.Tsuge $T$, Hagiwara Y. Influence of lateraloblique cyclic loading on abutment screw loosening of internal and external hexagon implants. Dent Mater J. 2009;28(4):373-81.

24.Junqueira MC, Ribeiro RF, Faria AC, Macedo AP, Almeida RP. Screw loosening of different UCLA-type abutments after mechanical cycling. Braz J Oral Sci. 2013 Sep;12(3):228-32.

25.Kitagawa T, Tanimoto Y, Odaki M, Nemoto $\mathrm{K}$, Aida M. Influence of implant/abutment joint designs on abutment screw loosening in a dental implant system. J Biomed Mater Res B Appl Biomater. 2005 Nov;75(2):457-63.

26. Gracis S, Michalakis K, Vigolo P, Vult von Steyern P, Zwahlen M, Sailer I. Internal vs. external connections for abutments/reconstructions: a systematic review. Clin Oral Implants Res. 2012 Oct;23:202-16.

27.Kwon JH, Han $\mathrm{CH}$, Kim SJ, Chang JS. The change of rotational freedom following different insertion torques in three implant systems with implant driver. J Adv Prosthodont. 2009 Mar 1;1(1):37-40.

28. Cho WR, Huh YH, Park CJ, Cho LR. Effect of cyclic loading and retightening on reverse torque value in external and internal implants. J Adv Prosthodont. 2015 Aug;7(4):288-93.

29.Feitosa PC, de Lima AP, Silva-Concílio LR, Brandt WC, Neves AC. Stability of external and internal implant connections after a fatigue test. Eur J Dent. 2013 Jul;7(3):267. 
30. Tsuruta K, Ayukawa Y, Matsuzaki T, Kihara M, Koyano K. The influence of implant-abutment connection on the screw loosening and microleakage. Int J Implant Dent. 2018 Apr 9;4(1):11.

31.Zarbakhsh A, Mazaheri Tehrani A, Shamshirgar F, Khosroshahi H. Effect of GapSeal ${ }^{\circledR}$ as a Sealing Material on Microgap and Microleakage at External Hexagon Implant Connections Following Cyclic Loading: An In Vitro Study. J Res Dentomaxillofac Sci. 2018;3(3):42-48.

32.Benjaboonyazit K, Chaijareenont $\mathrm{P}$, Khongkhunthian P. Removal torque pattern of a combined cone and octalobule index implant-abutment connection at different cyclic loading: an in-vitro experimental study. Int J Implant Dent. 2019 Jan 14;5(1):1.

Please cite this paper as:

Jalalian E, Hashemi E, Naser Mostufi S, Banifatemeh A, Shariati M, Alizadeh S. Effect of Abutment Connection Type and Cyclic Loading on Removal Torque Value. J Res Dentomaxillofac Sci. 2019; 4 (1) :36-40 